Int. J. Electrochem. Sci., 14 (2019) 2589 - 2605

\title{
Effect of pre-corrosion on Electrochemical Corrosion and Fatigue Behavior of S135 High-Strength Drill Pipe Steel in Marine Environment
}

\author{
Sheji Luo ${ }^{1, *}$, Ming Liu ${ }^{2,3,{ }^{*}, \text { Ninhua Wen }}{ }^{4}$, Yi Shen ${ }^{1}$, Yanming Liu ${ }^{1}$, Xiuzhou lin ${ }^{5}$ \\ ${ }^{1}$ School of Materials Science and Engineering, Xi'an Shiyou University, Xi'an 710065, PR China \\ ${ }^{2}$ State Key Laboratory for Mechanical Structure Strength and Vibration Xi'an Jiaotong University, \\ Xi'an 710049, PR China \\ ${ }^{3}$ MOE Key Laboratory for Multifunctional Materials and Structures, Xi'an Jiaotong University, Xi'an \\ 710049, PR China \\ ${ }^{4}$ Anke Engineering Technology Research Institute (Beijing) Co, Ltd., Beijing, 100083, PR China \\ ${ }^{5}$ Material Corrosion and Protection Key Laboratory of Sichuan province, Sichuan University of \\ Science and Engineering, Zigong 643000, PR China \\ *E-mail: sjluo@xsyu.edu.cn (Sheji Luo), liuming0313@xjtu.edu.cn (Ming Liu)
}

doi: $10.20964 / 2019.03 .69$

Received: 5 November 2018 / Accepted: 17 December 2018 / Published: 7 February 2019

The pre-corrosion on electrochemical corrosion and fatigue behaviors of S135 drill pipe steel were tested in simulated marine environment. The results shows that no passivation can be observed. With the extension of the immersion time, open circuit potential of the steel moves to the negative direction, the charge transfer resistance decreases, and both the corrosion current density and the corrosion rate increase. With the increasing of the pre-corrosion time, more larger and deeper corrosion pits are formed, the corrosion products are mainly constituted of $\mathrm{Fe}_{2} \mathrm{O}_{3}, \mathrm{FeO}(\mathrm{OH})$ and $\mathrm{Fe}_{3} \mathrm{O}_{4}$, which are porous and not adhering tightly to the steel substrate. With the increasing of the immersion time, the fatigue life of S135 steel is significantly reduced, and the fatigue cracks initiate at or near the corrosion pits and multiple crack sources could be observed. Cleavage steps and fatigue striations are the main features in the crack propagation zone, the fatigue striations become more obvious and the spacing of striations become smaller with the decreasing of stress amplitudes.

Keywords: S135 drill pipe steel; marine enviroment; fatigue lives; corrosion pit

\section{$\underline{\text { FULL TEXT }}$}

(C) 2019 The Authors. Published by ESG (www.electrochemsci.org). This article is an open access article distributed under the terms and conditions of the Creative Commons Attribution license (http://creativecommons.org/licenses/by/4.0/). 